\title{
Empagliflozin and Cardio-renal Outcomes in Patients with Type 2 Diabetes and Cardiovascular Disease - Implications for Clinical Practice
}

\author{
David H Fitchett \\ Division of Cardiology, St Michael's Hospital, University of Toronto, Ontario, Canada
}

\begin{abstract}
n patients with type 2 diabetes (T2D), the excretion of glucose by the kidney with sodium-glucose cotransporter 2 (SGLT2) inhibitors lowers glycosylated haemoglobin (HbA1c) levels, decreases body weight and visceral adiposity, as well as improving cardio-renal haemodynamics.

Currently, four SGLT2 inhibitors are approved in the US and Europe to improve glycaemic control -empagliflozin, dapagliflozin, canagliflozin, and ertuglifozin. Recently, the SGLT2 inhibitor empagliflozin was approved by the FDA for the reduction of cardiovascular (CV) death in adults with T2D and CV disease (CVD). This approval was based on the findings of the Empagliflozin, Cardiovascular Outcomes, and Mortality in Type 2 Diabetes (EMPA-REG OUTCOME) study, which was the first study to show a significant reduction of a primary CV endpoint with a glucose-lowering agent. In this study, the primary outcome (CV mortality, non-fatal myocardial infarction [MI] and non-fatal stroke) was reduced by empagliflozin $(10.5 \%$; 490/4,687) compared with placebo $(12.1 \%$; 282/2,333); hazard ratio (HR), 0.86 (95\% confidence interval [Cl]: $0.74,0.99)$. The primary outcome was driven by a large reduction of CV mortality (relative risk reduction [RRR], 38\%). Empagliflozin also reduced all-cause mortality (RRR, 32\%). Furthermore, empagliflozin reduced the adjudicated outcome of heart failure (HF) hospitalisation by $35 \%$ (HR, 0.65; 95\% Cl: 0.50, 0.85). Other non-adjudicated measures of HF outcomes were similarly reduced including investigator reported HF, the introduction of loop diuretics and death from HF. In the analysis of renal outcomes, incident or worsening nephropathy was reduced for empagliflozin (12.7\%) compared with placebo (18.8\%); HR, 0.61 (95\% Cl: 0.53, 0.70). Empagliflozin significantly reduced the risk of progression to macroalbuminuria (38\%) and doubling of creatinine (44\%), as well as the need of starting renal-replacement therapy (55\%). The benefits of empagliflozin for the reduction of CV death, all-cause death and hospitalisation for HF were observed across a range of baseline subgroups such as HbA1c level and renal function (down to estimated glomerular filtration rate [eGFR] $30 \mathrm{ml} / \mathrm{min}^{\prime} 1.73 \mathrm{~m}$ ). The rapid reduction of HF outcomes with empagliflozin is observed across the spectrum of CVD and HF risk and represents a therapeutic advance in the prevention and perhaps also in the treatment of HF, an often poorly recognised complication of T2D. This review discusses the EMPA-REG OUTCOME study and the implications for treating patients with T2D and CVD.
\end{abstract}

\section{Keywords}

Empagliflozin, SGLT2 inhibitor, type 2 diabetes,

cardiovasular, heart failure, outcomes

Disclosures: David H Fitchett discloses CME and consulting honoraria from Boehringer Ingelheim, Lilly, AstraZeneca, Sanofi and Amgen.

Review Process: Double-blind peer review.

Acknowledgements: The author critically reviewed the manuscript and approved the final version for submission. Editorial assistance was provided by Annick Moon of Moon Medical Communications Ltd., funded by Boehringer Ingelheim.

Authorship The named author met the International Committee of Medical Journal Editors (ICMJE) criteria for authorship of this manuscript, and took responsibility for the integrity of the work as a whole, and gave final approval to the version to be published.

open Access: This article is published under the Creative Commons

Attribution Noncommercial License, which permits any non-commercial

use, distribution, adaption and reproduction provided the original author(s)

and source are given appropriate credit. (C) The Authors 2018.

Received: 19 April 2018

Accepted: 22 May 2018

Citation: European Endocrinology. 2018;14(2):40-9

Correspondence: David H Fitchett, Division of Cardiology, St Michael's Hospital, 30 Bond Street, Toronto, Ontario M5B 1W8, Canada. E: fitchettd@smh.ca

Support: The publication of this article was supported by Boehringer Ingelheim.
Type 2 diabetes (T2D) is a major risk factor for cardiovascular diseases (CVDs) such as stroke, myocardial infarction (MI) and peripheral vascular disease, as well as an independent risk factor for heart failure (HF). ${ }^{1,2}$ Patients with T2D and established CVD have a substantial reduction of life expectancy (for example, a 60-year-old man with CVD and T2D has a 12-year reduction compared with individuals without diabetes). ${ }^{2}$ The prognosis for patients with comorbid HF and T2D is particularly poor, with a median survival of about 4 years. ${ }^{3}$

CVD prevention in patients with diabetes starts with the aggressive reduction of CVD risk factors. The Steno-2 study evaluated an intensive risk factor management strategy including lifestyle changes, as well as blood pressure (BP), lipid and glycaemic control in patients with T2D at high CVD risk. ${ }^{4}$ The study showed that more intensive risk factor management halved the occurrence of adverse CVD outcomes. A long-term followup of the Steno-2 patients showed that life expectancy was more than 7 years longer in patients in the more intensively managed group. ${ }^{4}$ Studies that have compared intensive glucose lowering with a less intensive strategy over a period of $<5$ years have not shown consistent reductions of CV events. ${ }^{5-10}$ Moreover, the Action to Control Cardiovascular Risk in Diabetes (ACCORD) trial was prematurely terminated because of increased mortality in the group receiving intensive blood glucose control. ${ }^{11}$ In extension long-term follow-up studies of ACCORD and Action in Diabetes and Vascular Disease: Preterax and Diamicron MR Controlled Evaluation (ADVANCE), early intensive glucose control was associated with a later improvement in CV outcomes, including a reduction of CV mortality long after the treatment allocation had ended. ${ }^{11,12}$ 
For individual glucose-lowering agents, until recently only subsidiary studies or secondary outcomes had shown CVD benefit. In a small sub-study of the United Kingdom Prospective Diabetes Study (UKPDS) of 342 overweight patients with T2D, intensive glucose-lowering with metformin compared with dietary restrictions alone, reduced the risk of $\mathrm{Ml}$ and all-cause death after 10 years. ${ }^{13}$ In the PROspective pioglitAzone Clinical Trial In macrovascular Events (PROACTIVE) study of pioglitazone in high-risk CVD patients, the study result was neutral, as the multicomponent primary endpoint was not significantly reduced. Yet the more conventional outcome (a secondary endpoint) of CV mortality, non-fatal $\mathrm{Ml}$ and stroke was reduced by $16 \%$ (hazard ratio [HR], 0.84; 95\% confidence interval [Cl]: 0.72, 0.98; $p=0.027) .{ }^{5}$

The 2015 Empagliflozin, Cardiovascular Outcomes, and Mortality in Type 2 Diabetes (EMPA-REG OUTCOME) study with the sodium-glucose cotransporter 2 (SGLT2) inhibitor empagliflozin was the first glucose-lowering clinical trial to show a significant reduction of the primary CV endpoint. ${ }^{14}$ Since then, three further studies with diabetes agents have demonstrated significant reductions of the 3-point Major Adverse Cardiac Events (MACE) outcome: with the glucagon-like peptide-1 (GLP-1) agonist semaglutide (Cardiovascular and Other Longterm Outcomes With Semaglutide in Subjects With Type 2 Diabetes [SUSTAIN-6] study), liraglutide (Liraglutide Effect and Action in Diabetes: Evaluation of Cardiovascular Outcome Results [LEADER] study), and with the SGLT2 inhibitor canagliflozin (Canagliflozin Cardiovascular Assessment Study [CANVAS] study). ${ }^{7,14-16}$

\section{Sodium-glucose cotransporter 2 and glucose homeostasis}

The SGLT2 is found almost exclusively in segment one of the proximal tubule and is a high-capacity, low-affinity transporter, which reabsorbs filtered glucose and sodium in equimolar amounts. ${ }^{17}$ Under physiological conditions, glucose reabsorption by SGLT2 accounts for about $90 \%$ of glucose re-uptake, with SGLT1 transporters reabsorbing the residual glucose in segment three of the proximal tubule. ${ }^{17-19}$

In hyperglycaemic conditions, SGLT2 expression is up-regulated, increasing both glucose and sodium reabsorption.20 The SGLT2 inhibitors reduce the capacity of the proximal tubule to reabsorb glucose, resulting in urinary glucose excretion. The urinary glucose loss lowers blood glucose and consequently reduces glycosylated haemoglobin ( $\mathrm{HbA1C}$ ) and insulin levels. ${ }^{21}$ As the mechanism of glucose lowering is independent of insulin action, SGLT2 inhibitors can be combined with all classes of glucose-lowering agents, with a low incidence of hypoglycaemia. ${ }^{22}$ Beyond glycaemic control, the clinical effects of the SGLT2 inhibitors reduce BP, decrease body weight and visceral adiposity and reduce albuminuria and circulating uric acid levels.

Currently, there are four SGLT2 inhibitors approved in Europe and the US for the treatment of T2D as an adjunct to diet and exercise to improve glycaemic control; these include empagliflozin, canagliflozin, dapagliflozin and ertugliflozin.23-29 The main pharmacological difference between the agents is their specificity for the SGLT2 versus SGLT1 cotransporters: empagliflozin 1:5000; ertugliflozin >1:2000; dapagliflozin >1:1400; canagliflozin >1:160. ${ }^{30-33}$

\section{The Empagliflozin, Cardiovascular Outcomes and Mortality in Type 2 Diabetes (EMPA-REG OUTCOME) study}

The EMPA-REG OUTCOME study was a multicentre, randomised, double-blind, placebo-controlled study of empagliflozin in patients with
T2D and established CVD. A total of 7,028 patients from 42 countries were randomised to receive one of two doses of empagliflozin (10 or $25 \mathrm{mg}$ ) or placebo, which was added to optimal care for T2D and $\mathrm{CV}$ risk factors. The main statistical analysis was based on the pooled results of the empagliflozin $10 \mathrm{mg}$ or $25 \mathrm{mg}$ groups versus placebo. The median duration of follow-up was 3.1 years. ${ }^{14}$

\section{Population}

The study population at baseline was representative of T2D patients with typical clinical characteristics and current management of T2D and CV risk factors. ${ }^{14}$ The mean age of patients at study entry was 63 years, the mean body mass index was $30 \mathrm{~kg} / \mathrm{m}^{2}$, and just over half of the population had a duration of T2D for $>10$ years. CVD included multi-vessel coronary artery disease, single vessel coronary artery disease and provokable ischaemia, history of Ml, history of stroke and peripheral artery disease (Table 1). A total of $25 \%$ of patients had prior coronary bypass surgery and $10 \%$ had a history of HF. Anti-hypertensive medications included an angiotensin converting enzyme (ACE)-inhibitor/angiotensin receptor blocker (ARB) (81\%), beta-blocker (65\%), diuretic (44\%) and a calcium channel blocker (33\%), and the majority were receiving statins (>76\%). Glucose-lowering medications at baseline were metformin (74\%), insulin (48\%), sulfonylurea (43\%), dipeptidylpeptidase-4 (DPP-4) inhibitor (11\%), thiazolidinediones (4\%) and GLP-1 agonist (3\%). The mean baseline HbA1c levels were 8.08\% in the placebo group, and $8.07 \%$ in the empagliflozin group (Table 1). After the first 3 months' treatment with either empagliflozin or placebo, investigators were encouraged to adjust glucose-lowering medication to reduce $\mathrm{HbA} 1 \mathrm{C}$ levels to locally recommended targets using any choice of glucose-lowering agents. However, many patients did not reach these levels during the study and the adjusted mean HbA1c at week 206 was $7.81 \%$ in the empagliflozin group and $8.16 \%$ in the placebo group.

\section{Cardiovascular outcomes}

The primary outcome (CV mortality, non-fatal Ml and non-fatal stroke) was reduced by empagliflozin $(10.5 \%$; 490/4,687) compared with placebo (12.1\%; 282/2,333); HR, 0.86 (95\% Cl: 0.74, 0.99) (Figure 1a). The reduction of the primary outcome was driven by a $38 \%$ reduction of $\mathrm{CV}$ mortality (HR 0.62; 95\% Cl: 0.49, 0.77) with no significant reduction of either Ml or stroke. The reduction of $\mathrm{CV}$ mortality by empagliflozin was seen very early (after less than 3 months treatment) (Figure 1b), and the widening of the difference between the treatment and placebo survival curves indicates an on-going treatment benefit. Empagliflozin also reduced all-cause mortality by $32 \%$ (HR $0.68 ; 95 \% \mathrm{Cl}: 0.57,0.82$ ). The reduction of $\mathrm{CV}$ death was observed across a wide range of subgroups such as baseline CVD, gender, age, high or low HbA1c levels, reduction of $\mathrm{HDA} 1 \mathrm{C}$ and renal function. ${ }^{14,34,35}$

\section{Heart failure outcomes}

Empagliflozin reduced the adjudicated outcome of HF hospitalisation by $35 \%$ (HR, 0.65 ; $95 \% \mathrm{Cl}: 0.50,0.85)$. Other non-adjudicated measures of HF outcomes, including investigator-reported HF, the introduction of loop diuretics and death from HF were significantly reduced by empagliflozin (Table 2) ${ }^{34}$ The rate of HF hospitalisation or CV death was lower for empagliflozin (5.7\%) versus placebo (8.5\%); HR, 0.66 (95\% Cl: 0.55, 0.79), with consistent benefits across subgroups including age, race, estimated glomerular filtration rate (eGFR), use of glucose-lowering medication (including insulin), CV medications and diuretics. Among patients who were hospitalised for $\mathrm{HF}$, a smaller proportion receiving empagliflozin died of CV causes (13.5\%) than those on placebo (24.2\%). Similar reductions of CV mortality and HF outcomes were observed in the $10 \%$ of patients with a baseline history of HF as in the overall group. 
Table 1: Baseline characteristics in the total population in the EMPA-REG OUTCOME study

\begin{tabular}{|c|c|c|}
\hline & $\begin{array}{l}\text { Empagliflozin } \\
\text { (10 mg and } 25 \text { mg pooled) } \\
n=4,687\end{array}$ & $\begin{array}{l}\text { Placebo } \\
n=2,333\end{array}$ \\
\hline Mean age; years (SD) & $63.1( \pm 8.6)$ & $63.2( \pm 8.8)$ \\
\hline Male, n (\%) & 3,336 (71.2) & $1,680(72.0)$ \\
\hline $\begin{array}{l}\text { Race, } \mathrm{n}(\%) \\
\text { White } \\
\text { Asian } \\
\text { Black/African-American } \\
\text { Other/missing }\end{array}$ & $\begin{array}{l}3,403(72.6) \\
1,006(21.5) \\
237(5.1) \\
41(0.9)\end{array}$ & $\begin{array}{l}1,678(71.9) \\
511(21.9) \\
120(5.1) \\
24(1.0)\end{array}$ \\
\hline $\begin{array}{l}\text { Ethnicity, } \mathrm{n}(\%) \\
\text { Not Hispanic or Latino } \\
\text { Hispanic or Latino } \\
\text { Missing }\end{array}$ & $\begin{array}{l}3,835(81.8) \\
847(18.1) \\
5(0.1)\end{array}$ & $\begin{array}{l}1,912(82.0) \\
418(17.9) \\
3(0.1)\end{array}$ \\
\hline $\begin{array}{l}\text { Region, } n(\%) \\
\text { Europe } \\
\text { North America, Australia and New Zealand } \\
\text { Asia } \\
\text { Latin America } \\
\text { Africa }\end{array}$ & $\begin{array}{l}1,926(41.1) \\
932(19.9) \\
897(19.1) \\
721(15.4) \\
211(4.5)\end{array}$ & $\begin{array}{l}959(41.1) \\
462(19.8) \\
450(19.3) \\
360(15.4) \\
102(4.4)\end{array}$ \\
\hline Weight; kg (SD) & $86.2( \pm 18.9)$ & $86.6( \pm 19.1)$ \\
\hline Body mass index; kg/m² (SD) & $30.6( \pm 5.3)$ & $30.7( \pm 5.2)$ \\
\hline $\begin{array}{l}\text { CV risk factor, } \mathrm{n}(\%) \\
\text { Coronary artery disease } \\
\text { Multi-vessel coronary artery disease } \\
\text { History of myocardial infarction } \\
\text { Coronary artery bypass graft } \\
\text { History of stroke } \\
\text { Peripheral artery disease } \\
\text { Single vessel coronary artery disease }{ }^{\ddagger} \\
\text { Cardiac failure }\end{array}$ & $\begin{array}{l}4,657(99.4) \\
3,545(75.6) \\
2,179(46.5) \\
22,190(46.7) \\
1,175(25.1) \\
1,084(23.1) \\
982(21.0) \\
498(10.6) \\
462(9.9)\end{array}$ & $\begin{array}{l}2,307(98.9) \\
1,763(75.6) \\
1,100(47.1) \\
1,083(46.4) \\
563(24.1) \\
553(23.7) \\
479(20.5) \\
238(10.2) \\
244(10.5)\end{array}$ \\
\hline Glycosylated haemoglobin \% (SD) & $8.07( \pm 0.85)$ & $8.08( \pm 0.84)$ \\
\hline $\begin{array}{l}\text { Time since diagnosis of type } 2 \text { diabetes, } n(\%) \\
\quad \leq 1 \text { years } \\
\quad>1-5 \text { years } \\
\quad>5-10 \\
>10 \text { years }\end{array}$ & $\begin{array}{l}128(2.7) \\
712(15.2) \\
1,175(25.1) \\
2,672(57.0)\end{array}$ & $\begin{array}{l}52(2.2) \\
371(15.9) \\
571(24.5) \\
1,339(57.4)\end{array}$ \\
\hline $\begin{array}{l}\text { Glucose-lowering therapy, } \mathrm{n} \text { (\%) } \\
\text { Medication taken alone or in combination } \\
\text { Metformin } \\
\text { Insulin } \\
\text { Median daily dose, IU } \\
\text { Sulfonylurea } \\
\text { Dipeptidyl peptidase-4 inhibitor } \\
\text { Thiazolidinedione } \\
\text { Glucagon-like peptide-1 agonist } \\
\text { Monotherapy } \\
\text { Dual therapy }\end{array}$ & $\begin{array}{l}3,459(73.8) \\
2,252(48.0) \\
54.0 \\
2,014(43.0) \\
529(11.3) \\
198(4.2) \\
126(2.7) \\
1,380(29.4) \\
2,259(48.2)\end{array}$ & $\begin{array}{l}1,734(74.3) \\
1,135(48.6) \\
52.0 \\
992(42.5) \\
267(11.4) \\
101(4.3) \\
70(3.0) \\
691(29.6) \\
1,148(49.2)\end{array}$ \\
\hline $\begin{array}{l}\text { Anti-hypertensive therapy, } \mathrm{n} \text { (\%) } \\
\text { ACE/angiotensin receptor blockers } \\
\text { Beta-blockers } \\
\text { Diuretics } \\
\text { Calcium channel blockers } \\
\text { Mineralocorticoid receptor antagonists } \\
\text { Renin inhibitors } \\
\text { Other }\end{array}$ & $\begin{array}{l}4,446(94.9) \\
3,798(81.0) \\
3,056(65.2) \\
2,047(43.7) \\
1,529(32.6) \\
305(6.5) \\
27(0.6) \\
383(8.2)\end{array}$ & $\begin{array}{l}2,221(95.2) \\
1,868(80.1) \\
1,498(64.2) \\
988(42.3) \\
788(33.8) \\
136(5.8) \\
19(0.8) \\
191(8.2)\end{array}$ \\
\hline $\begin{array}{l}\text { Lipid-lowering therapy, n (\%) } \\
\text { Statins } \\
\text { Fibrates } \\
\text { Ezetimibe } \\
\text { Niacin } \\
\text { Other }\end{array}$ & $\begin{array}{l}3,820(81.5) \\
3,630(77.4) \\
431(9.2) \\
189(4.0) \\
91(1.9) \\
365(7.8)\end{array}$ & $\begin{array}{l}1,864(79.9) \\
1,773(76.0) \\
199(8.5) \\
81(3.5) \\
35(1.5) \\
175(7.5)\end{array}$ \\
\hline
\end{tabular}




\begin{tabular}{|c|c|c|}
\hline $\begin{array}{l}\text { Anti-coagulants, n (\%) } \\
\text { Acetylsalicylic acid } \\
\text { Clopidogrel } \\
\text { Vitamin K antagonists }\end{array}$ & $\begin{array}{l}4,162(88.8) \\
3,876(82.7) \\
494(10.5) \\
266(5.7)\end{array}$ & $\begin{array}{l}2,090(89.6) \\
1,927(82.6) \\
249(10.7) \\
156(6.7)\end{array}$ \\
\hline Systolic blood pressure mmHg (SD) & $135.3( \pm 16.9)$ & $135.8( \pm 17.2)$ \\
\hline Diastolic blood pressure mmHg (SD) & $76.6( \pm 9.7)$ & $76.8( \pm 10.1)$ \\
\hline Total cholesterol mg/dL (SD) & $163.5( \pm 44.2)$ & $161.9( \pm 43.1)$ \\
\hline Low density lipoprotein cholesterol mg/dL (SD) & $85.9( \pm 36.0)$ & $84.9( \pm 35.3)$ \\
\hline High density lipoprotein cholesterol mg/dL (SD) & $44.6( \pm 11.9)$ & $44.0( \pm 11.3)$ \\
\hline Triglycerides mg/dL (SD) & $170.5( \pm 129.7)$ & $170.7( \pm 121.2)$ \\
\hline Estimated GFR rate mL/min/1.73 m² (SD) & $74.2( \pm 21.6)$ & $73.8( \pm 21.1)$ \\
\hline $\begin{array}{l}\text { Estimated GFR, n (\%) } \\
\qquad 90 \mathrm{~mL} / \mathrm{min} / 1.73 \mathrm{~m}^{2} \\
\quad 60-<90 \mathrm{~mL} / \mathrm{min} / 1.73 \mathrm{~m}^{2} \\
<60 \mathrm{~mL} / \mathrm{min} / 1.73 \mathrm{~m}^{2}\end{array}$ & $\begin{array}{l}1,050(22.4) \\
2,423(51.7) \\
1,212(25.9)\end{array}$ & $\begin{array}{l}488(20.9) \\
1,238(53.1) \\
607(26.0)\end{array}$ \\
\hline $\begin{array}{l}\text { Urine albumin-creatinine ratio, n (\%) } \\
\qquad 30 \mathrm{mg} / \mathrm{g} \\
30-300 \mathrm{mg} / \mathrm{g} \\
>300 \mathrm{mg} / \mathrm{g}\end{array}$ & $\begin{array}{l}2,789(59.5) \\
1,338(28.5) \\
509(10.9)\end{array}$ & $\begin{array}{l}1,382(59.2) \\
675(28.9) \\
260(11.1)\end{array}$ \\
\hline
\end{tabular}

Reproduced with permission from Zinman et al., $2015 .{ }^{14} \mathrm{ACE}=$ angiotensin-converting enzyme inhibitors; $C V=$ cardiovascular; GFR = glomerular filtration rate; IU = international units; $S D=$ standard deviation.

Figure 1: Kaplan-Meier estimates of time to 3-point MACE outcome (A) and cardiovascular death (B) in the EMPA-REG OUTCOME study

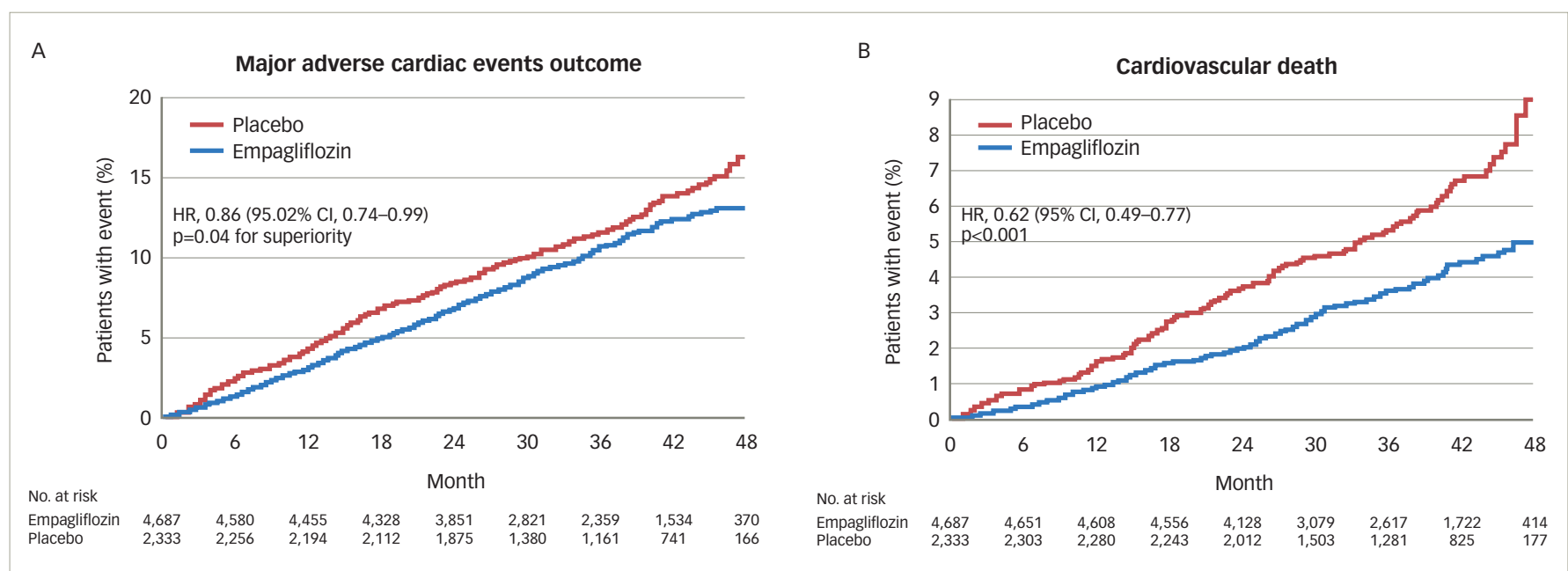

Reproduced with permission from Zinman et al., $2015 .{ }^{14} \mathrm{Cl}=$ confidence interval; $\mathrm{CV}=$ cardiovascular; EMPA-REG OUTCOME = empagliflozin, cardiovascular outcomes, and mortality in type 2 diabetes study; HR = hazard ratio; $M A C E=$ major adverse cardiac events; No. = number.

The CV benefits of empagliflozin were also observed in patients across the spectrum of risk for $\mathrm{HF}^{36}$ In the overall population, using the Clinical Health Aging and Body Composition HF risk score, the reduction in $\mathrm{CV}$ death and HF hospitalisation for empagliflozin versus placebo was consistent across the risk subgroups, with a $\mathrm{HR}(95 \% \mathrm{Cl})$ of $0.71(0.52$, $0.96)$ in the low-to-average-risk group, $0.52(0.36,0.75)$ in the high-risk group, and $0.55(0.30,1.00)$ in the very high-risk group; a similar reduction was observed for HF hospitalisation (Figure 2).

A total of 958 (13.6\%) patients had a HF burden (HF at baseline, HF hospitalisation or HF reported by the investigator as an adverse event). The rate of $\mathrm{CV}$ death was almost four-fold greater in patients with a HF burden, with $38 \%$ of all CV deaths in the EMPA-REG OUTCOME trial occurring in this minority group. Although the absolute benefit of empagliflozin was larger (4.9\%) in the group with a HF burden $(10.4 \%$ versus $15.3 \%$, respectively; $\mathrm{HR}, 0.67 ; 95 \% \mathrm{Cl}: 0.47,0.97)$, patients with no HF burden had an important mortality benefit (2.7\% versus $4.2 \%$, respectively; HR, $0.63 ; 95 \% \mathrm{Cl}: 0.48,0.84)$.

\section{Renal outcomes}

Chronic kidney disease (CKD) is a major co-morbidity in patients with T2D, adding to the burden of disease and increasing the risk of death. It is estimated that about $40 \%$ of patients with T2D have CKD with urinary albumin/creatinine ratio $\geq 30 \mathrm{mg} / \mathrm{g}$ and/or eGFR $\geq 60 \mathrm{ml} / \mathrm{min} / 1.73 \mathrm{~m}^{2}$, and $20 \%$ of patients with T2D have clinically overt CKD (eGFR $<60 \mathrm{~mL} / \mathrm{min} / 1.73 \mathrm{~m}^{2}$ ). ${ }^{37,38}$ Despite intensive glucose-lowering strategies and the use of renin-angiotensin-aldosterone system (RAAS) agents, patients with T2D remain at increased risk of progressive renal disease, the need for dialysis and renal death. ${ }^{12,39-42}$

In the EMPA-REG OUTCOME study, the composite renal outcome was the rate of incident or worsening nephropathy defined as progression 
Table 2: Heart failure outcomes and all-cause hospitalisation in the EMPA-REG OUTCOME study

\begin{tabular}{|c|c|c|c|c|c|c|}
\hline & \multicolumn{2}{|c|}{ Placebo $(n=2,333)$} & \multicolumn{2}{|c|}{ Empagliflozin $(n=4,687)$} & \multirow[t]{2}{*}{$\mathrm{HR}(95 \% \mathrm{Cl})$} & \multirow[t]{2}{*}{ p-value } \\
\hline & $n(\%)$ & $\begin{array}{l}\text { Rate/1,000 } \\
\text { patient-year }\end{array}$ & $\mathrm{n}(\%)$ & $\begin{array}{l}\text { Rate/1,000 } \\
\text { patient-years }\end{array}$ & & \\
\hline Heart failure hospitalisation or CV death & $198(8.5)$ & 30.1 & $265(5.7)$ & 19.7 & $0.66(0.55,0.79)$ & $<0.001$ \\
\hline Hospitalisation for death from heart failure & $104(4.5)$ & 15.8 & $129(2.8)$ & 9.6 & $0.61(0.47,0.79)$ & $<0.001$ \\
\hline Hospitalisation for heart failure & $95(4.1)$ & 14.5 & $126(2.7)$ & 9.4 & $0.65(0.50,0.85)$ & 0.002 \\
\hline Investigator-reported heart failure ${ }^{a}$ & $143(6.1)$ & 22.0 & $204(4.4)$ & 15.3 & $0.70(0.56,0.87)$ & 0.001 \\
\hline Investigator-reported serious heart failurea,b & $136(5.8)$ & 20.9 & $192(4.1)$ & 14.4 & $0.69(0.55,0.86)$ & 0.001 \\
\hline All-cause hospitalisation & $925(39.6)$ & 183.3 & $1,725(36.8)$ & 161.9 & $0.89(0.82,0.96)$ & 0.003 \\
\hline
\end{tabular}

Reproduced with permission from Fitchett et al., 2016. ${ }^{34}$ aBased on narrow standardised MedDRA query 'cardiac failure', preferred terms: acute pulmonary oedema; cardiac failure; cardiac failure acute; cardiac failure chronic; cardiac failure, congestive; cardiogenic shock; cardiopulmonary failure; left ventricular failure; pulmonary oedema; right ventricular failure. ${ }^{b}$ Adverse events reported as serious adverse events by investigator. Parents treated with at least one dose of study drugs. $\mathrm{Cl}=\mathrm{Confidence} \mathrm{interval;}$ $C V=$ cardiovascular; EMPA-REG OUTCOME = empagliflozin, cardiovascular outcomes and mortality in type 2 diabetes study; HR = hazard ratio; MedDRA = Medical Dictionary for Regulatory Activities.

Figure 2: Risk reduction of heart failure over time for empagliflozin versus placebo in the EMPA-REG OUTCOME study

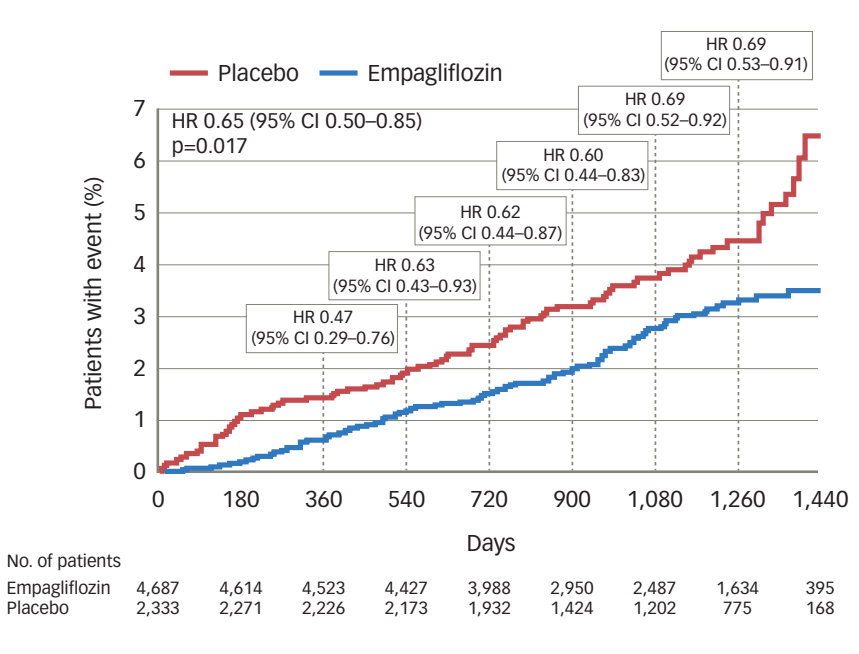

Reproduced with permission from Fitchett et al., $2018 .{ }^{36} \mathrm{Cl}=$ confidence interval; EMPA-REG OUTCOME = empagliflozin, cardiovascular outcomes, and mortality in type 2 diabetes study; $H R$ = hazard ratio; No. = number.

to macroalbuminuria, doubling of creatinine level, with eGFR of $\leq 45 \mathrm{ml} / \mathrm{min} / 1.73 \mathrm{~m}^{2}$, the initiation of dialysis, or death from renal disease. ${ }^{35}$ Incident or worsening nephropathy was reduced with empagliflozin (12.7\%) versus placebo (18.8\%); HR, 0.61 (95\% Cl: 0.53, 0.70). The post-hoc renal composite outcomes were: doubling of serum creatinine level, the initiation of renal-replacement therapy or death from renal disease. The risk of these outcomes was reduced for empagliflozin versus placebo by $46 \%{ }^{35}$ Empagliflozin reduced the risk of progression to macroalbuminuria by $38 \%$, the risk of a doubling of creatinine by $44 \%$ and the risk of starting renal-replacement therapy by 55\%. Furthermore, from the total population of 7,020 patients, 2,250 (67\%) had prevalent kidney disease at baseline defined as eGFR of $<60 \mathrm{~mL} / \mathrm{min} / 1.73 \mathrm{~m}^{2}$ and/or urine albumin-creatinine ratio (UACR) of $>300 \mathrm{mg} / \mathrm{g}$. In patients with prevalent kidney disease, empagliflozin reduced the risk of $\mathrm{CV}$ death by $29 \%$, the risk of all-cause death by $24 \%$, the risk of HF hospitalisation by $39 \%$ and the risk of all-cause hospitalisation by $19 \%$. These effects were observed across the range of baseline eGFR $(<45,45-<60,60-<90$, $\left.\geq 90 \mathrm{ml} / \mathrm{min} / 1.73 \mathrm{~m}^{2}\right)$, UACR status ( $>300,30-\leq 300,<30 \mathrm{mg} / \mathrm{g}$ ) and on top of a high use of RAAS inhibitors ( $80.7 \%$ were taking ACE inhibitors or ARBS).
Pre-specified and post-hoc analyses were performed to assess changes in UACR scores, according to baseline UACR status (normoalbuminuria: UACR $<30 \mathrm{mg} / \mathrm{g}$; microalbuminuria: UACR $\geq 30-\leq 300 \mathrm{mg} / \mathrm{g}$; and macroalbuminuria: UACR $>300 \mathrm{mg} / \mathrm{g}$ ). At baseline, $59 \%$ of patients had normoalbuminuria, 29\% microalbuminuria and $11 \%$ had macroalbuminuria. ${ }^{35,43}$ In patients with micro- or macro-albuminuria, there was a rapid reduction in UACR with empagliflozin versus placebo that was maintained at week 12 and week 164 (Figure 3). ${ }^{44}$

\section{The EMPA-REG OUTCOME study - discussion}

Improving survival and preventing hospital admission are key goals of the treatment of Co-morbid T2D and CVD. In the EMPA-REG OUTCOME study, empagliflozin reduced the risk of CV death by $38 \%$, any cause death by $32 \%$ and hospitalisation for HF by $35 \% .{ }^{14}$ Moreover, the rapid improvement in HF outcomes across the spectrum of HF risk with empagliflozin represents a therapeutic advance in the treatment of this poorly recognised major CV co-morbidity in T2D.,346 The reduction of $\mathrm{CV}$ mortality was observed when empagliflozin was given in addition to guideline recommended therapy to reduce CV risk, including statins, ACE inhibitors and ARBS.

The mechanism of action of SGLT2 inhibition for the reduction of CV events is uncertain; however, analyses have shown that improvements in glycaemic control or traditional CVD risk factors such as BP and lipids are unlikely to be involved. ${ }^{45} \mathrm{~A}$ mediation analysis indicates that more than $50 \%$ of the reduction of $\mathrm{CV}$ mortality and reduced $\mathrm{HF}$ admission was related to the observed increase in haematocrit. ${ }^{45}$ The sustained $4 \%$ increase of haematocrit observed in patients receiving empagliflozin was likely due to an estimated $7 \%$ reduction of plasma volume, which could reduce cardiac loading and might result in improved CV outcomes especially if cardiac function was abnormal. ${ }^{45}$ Other identified mediators were the reductions of uric acid and albuminuria. Although mediation analysis does not prove causality, it provides targets for future investigation. ${ }^{45}$ Other possible mechanisms of action include the increased availability of ketone bodies which may be a more efficient fuel for the stressed myocardium than free fatty acids, inhibition of the sodium hydrogen exchanger and modulating the effect of lectins. ${ }^{46-48}$

T2D is an independent risk factor for $\mathrm{HF}$, with rates of death and hospitalisation in patients with T2D and HF more than 50\% greater than in patients without diabetes. ${ }^{3,49-51}$ In a Swedish study of HF patients with T2D $(8,809)$ and without T2D $(27,465)$, the median survival time was 3.5 years versus 4.6 years, respectively, and the adjusted odds ratio 
Figure 3: Urinary albumin-to-creatinine ratio over time with empagliflozin versus placebo in patients with normoalbuminuria (A), microalbuminuria $(B)$ and macroalbuminuria $(C)$ at baseline in the EMPA-REG OUTCOME study

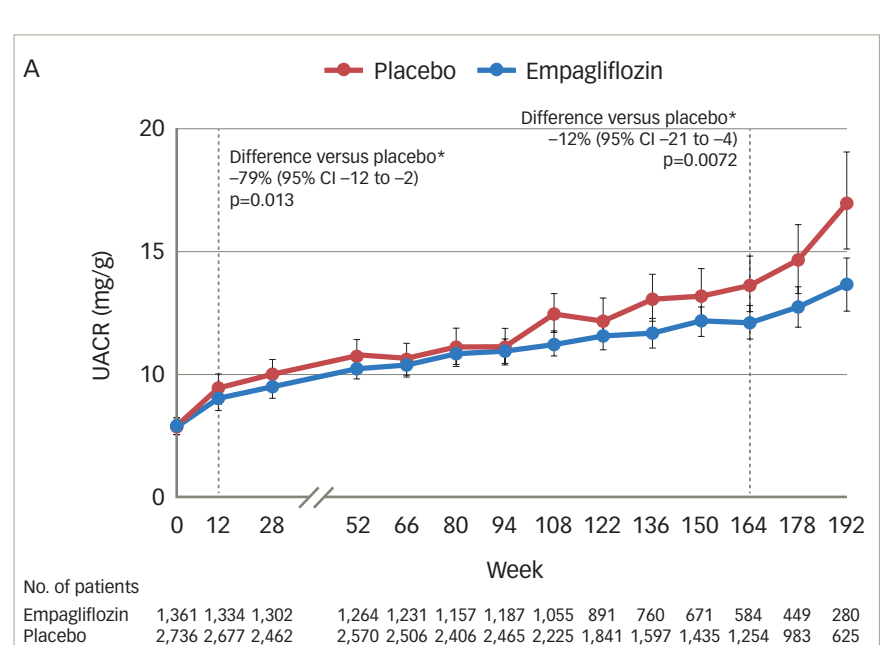

B

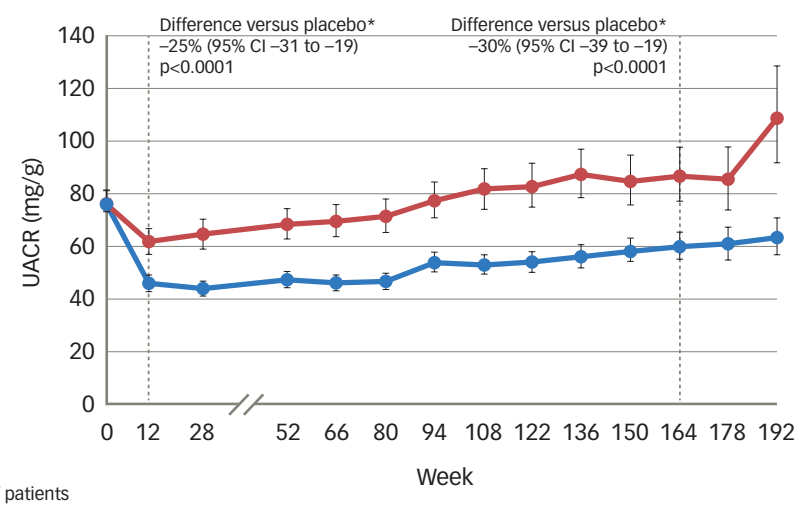
$\begin{array}{lcccccccccccccc}\text { Empagliflozin } & 658 & 643 & 631 & 612 & 588 & 546 & 570 & 506 & 426 & 376 & 330 & 291 & 213 & 128 \\ \text { Placebo } & 1,311 & 1,283 & 1,249 & 1,217 & 1,185 & 1,134 & 1,156 & 1,033 & 869 & 739 & 661 & 583 & 449 & 298\end{array}$

C

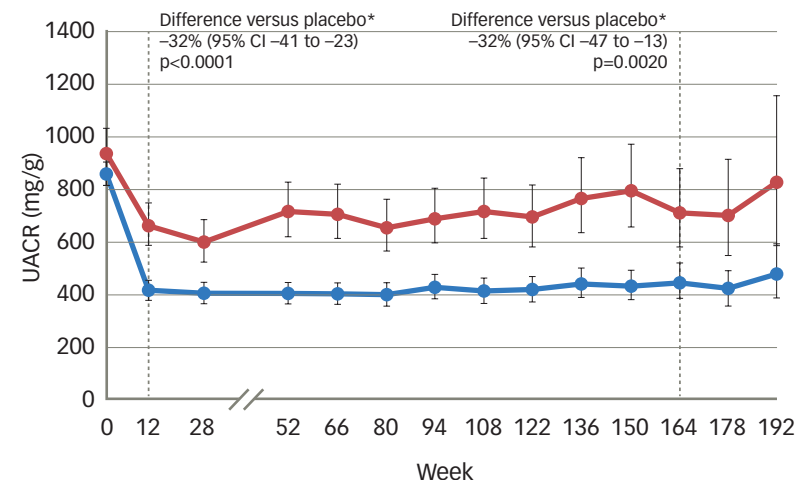

No. of patients

$\begin{array}{lllllllllllllll}\text { Empagliflozin } & 257 & 249 & 233 & 220 & 206 & 193 & 195 & 168 & 137 & 109 & 100 & 86 & 56 & 31\end{array}$ $\begin{array}{llllllllllllllll}\text { Placebo } & 498 & 480 & 477 & 452 & 435 & 404 & 425 & 377 & 324 & 265 & 241 & 206 & 157 & 96\end{array}$

Adjusted mean values and 95\% Cls are shown. Mixed model repeated measures analysis using all data obtained until study end in patients treated with at least one dose of study drug. Normoalbuminuria: UACR $<30 \mathrm{mg} / \mathrm{g}$. Microalbuminuria: UACR $\geq 30$ to $300 \mathrm{mg} / \mathrm{g}$. Macroalbuminura: UACR >300 mg/g. *placebo-corrected adjusted geometric mean ration $(95 \% \mathrm{Cl}$ ) of relative change from baseline with empagliflozin. 164 week (IQR 115-186) corresponds to the median observation period. Reproduced with permission from Cherney et al., 2017. ${ }^{44} \mathrm{Cl}=$ confidence interval; EMPA-REG

OUTCOME = empagliflozin, cardiovascular outcomes, and mortality in type 2 diabetes study; IQR = interquartile range; No. = number; UACR = urine albumin-creatinine ratio.

for death was 1.60 (95\% Cl: 1.50, 1.71).52 Furthermore, certain glucose lowering agents increase the risk of developing HF.11 In contrast, both in patients with and without a history of HF, empagliflozin reduced a range of HF outcomes. ${ }^{53}$ It is unknown whether these benefits occurred in patients with abnormal cardiac function or elevated Brain Naturetic Factor levels. Consequently, it is uncertain whether empagliflozin is beneficial in patients with HF with either preserved ejection fraction (HFpEF), or with reduced ejection fraction (HFrEF). In addition, it is not yet known whether empagliflozin is beneficial and safe in patients with established HF. Two phase III clinical trials are currently ongoing to assess empagliflozin in patients with either HFpEF or HFrEF and including patients with and without T2D (NCT03057977 and NCT03057951). Both trials will assess empagliflozin versus placebo for the prevention of $\mathrm{CV}$ death and HF hospitalisation and are expected to report in 2020.

In the analysis of renal outcomes, empagliflozin reduced the progression of nephropathy and death from renal disease, including in patients with prevalent kidney disease at baseline. ${ }^{35}$ The modest reduction of BP may have played a small role in preserving renal function. However, it is also possible that modulation of tubuloglomerular feedback by empagliflozin is important. In patients with diabetes, glomerular hypertension and hyperfiltration results from afferent glomerular arteriolar dilatation and efferent arteriolar constriction. ${ }^{54}$ The precise mechanism of the glomerular hemodynamic abnormalities is not yet defined. ${ }^{55}$ SGLT2 inhibition increases tubular sodium concentration which is sensed by the macula densa. Adenosine released by the macula densa constricts the afferent glomerular arteriole reducing glomerular hypertension and hyperfiltration, consequently stabilising renal function. ${ }^{56}$

\section{Empagliflozin - safety and tolerability}

The safety and tolerability of empagliflozin was recently assessed in a pooled analysis of 15 trials, and four extension studies including patients treated with empagliflozin $10 \mathrm{mg}$ or $25 \mathrm{mg}(n=4,221$ and $n=4,196$, respectively), or placebo $(n=4,203) .22$ The study showed that the incidence of confirmed hypoglycaemic events was similar for empagliflozin and placebo as an add-on to insulin or metformin with or without other glucose-lowering medication, yet the incidence of hypoglycaemia was higher when empagliflozin was added to sulfonylureas (Table ${ }^{322}$ ). Urinary tract infections (UTIS) were more common in women than men, with a similar incidence in the empagliflozin and placebo groups for both sexes (Table 3). The incidence of complicated UTIS, such as pyelonephritis, urosepsis or serious adverse events consistent with UTI, was $0.6 \%$ and $0.9 \%$ for empagliflozin 10 or $25 \mathrm{mg}$, respectively, and $0.9 \%$ for placebo. Genital mycotic infection was increased in both sexes and was more frequent in women than men (Table 414,16,57,58); however, infections were usually easy to treat and less than $10 \%$ of patients developing a genital infection had to discontinue treatment with empagliflozin.22 Furthermore, genital infections may be reduced by good perineal hygiene.

In the EMPA-REG OUTCOME trial, other safety adverse outcomes were not increased by empagliflozin including bone fractures, cancer events, renal adverse events (including acute kidney injury), thromboembolic events, hepatic injury, acute pancreatitis, lower limb amputations and diabetic ketoacidosis. ${ }^{14}$

\section{Empagliflozin - place in therapy Indications}

Empagliflozin was licenced in 2014 in the US and Europe as a treatment for adults with T2D, and indicated as an adjunct to diet and other glucoselowering agents to improve glycaemic control.27.28 In 2016, the FDA approved empagliflozin for the reduction of $\mathrm{CV}$ death in adult patients with T2D and CVD. In Europe, the EMA recognise the results of the EMPA-REG OUTCOME study and the reduction of CV mortality with empagliflozin. 
Table 3: Safety and tolerability of empagliflozin in patients with type 2 diabetes (pooled analysis of phase I-III trials)

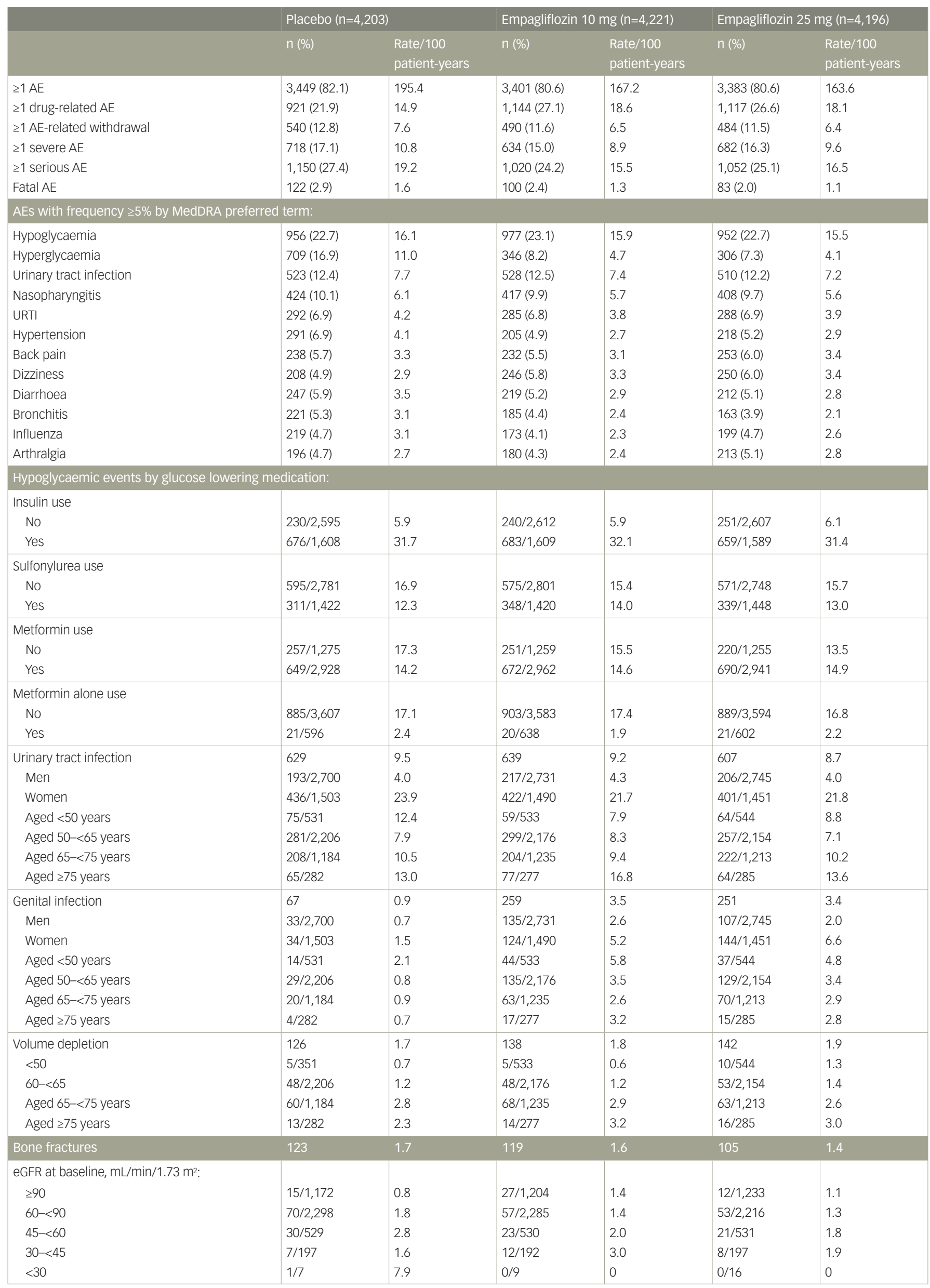




\begin{tabular}{|c|c|c|c|c|c|c|}
\hline $\begin{array}{l}\text { Cancer events: } \\
\text { Onset } \geq 6 \text { months from start of treatment/ } \\
\text { participants with exposure } \geq 6 \text { months } \\
\text { Bladder cancer } \\
\text { Renal cancer } \\
\text { Breast cancer } \\
\text { Melanoma } \\
\text { Lung cancer }\end{array}$ & $\begin{array}{l}95 \\
76 / 3,159 \\
2 \\
5 \\
4 \\
2 \\
7\end{array}$ & $\begin{array}{l}1.3 \\
1.4 \\
0.0 \\
0.1 \\
0.1 \\
<0.1 \\
0.1\end{array}$ & $\begin{array}{l}121 \\
103 / 3,270 \\
4 \\
4 \\
3 \\
4 \\
11\end{array}$ & $\begin{array}{l}1.6 \\
1.8 \\
0.1 \\
0.1 \\
0.1 \\
0.1 \\
0.2\end{array}$ & $\begin{array}{l}119 \\
86 / 3,203 \\
7 \\
3 \\
3 \\
3 \\
9\end{array}$ & $\begin{array}{l}1.5 \\
1.5 \\
0.1 \\
0.1 \\
0.1 \\
0.1 \\
0.2\end{array}$ \\
\hline Decreased renal function & 159 & 2.2 & 137 & 1.8 & 141 & 1.8 \\
\hline $\begin{array}{l}\text { eGFR, mL/min } / 1.73 \mathrm{~m}^{2} \text { : } \\
\geq 90 \\
60-<90 \\
45-<60 \\
30-<45 \\
<30\end{array}$ & $\begin{array}{l}13 / 1,172 \\
56 / 2,298 \\
55 / 529 \\
32 / 197 \\
3 / 7\end{array}$ & $\begin{array}{l}0.7 \\
1.4 \\
5.2 \\
7.9 \\
37.7\end{array}$ & $\begin{array}{l}9 / 1,204 \\
56 / 2,285 \\
45 / 530 \\
24 / 192 \\
3 / 9\end{array}$ & $\begin{array}{l}0.5 \\
1.4 \\
4.0 \\
6.2 \\
21.4\end{array}$ & $\begin{array}{l}10 / 1,233 \\
53 / 2,216 \\
42 / 531 \\
34 / 197 \\
2 / 16\end{array}$ & $\begin{array}{l}0.5 \\
1.3 \\
3.7 \\
8.9 \\
7.6\end{array}$ \\
\hline Acute kidney injury & 38 & 0.5 & 28 & 0.4 & 24 & 0.3 \\
\hline Hepatic injury & 151 & 2.1 & 106 & 1.4 & 127 & 1.7 \\
\hline Acute pancreatitis & 4 & 0.1 & 1 & $<0.1$ & 4 & 0.1 \\
\hline Diabetic ketoacidosis & 5 & 0.1 & 5 & 0.1 & 1 & $<0.1$ \\
\hline Venous thromboembolic events & 23 & 0.3 & 11 & 0.1 & 26 & 0.3 \\
\hline Lower limb amputations & 46 & & 46 & - & 48 & \\
\hline \multicolumn{7}{|c|}{ Events potentially related to lower limb amputations: } \\
\hline Peripheral artery obstructive disease events & 96 & - & 98 & - & 112 & - \\
\hline Diabetic foot-related events & 109 & - & 94 & - & 106 & - \\
\hline Relevant infection events & 74 & - & 79 & - & 80 & - \\
\hline
\end{tabular}

Reproduced with permission from Kohler et al., 2017.22 aln the opinion of the investigator. ${ }^{b} \mathrm{AE}$ that is incapacitating or causing inability to work or to perform usual activities. ${ }^{\prime} A E$ that results in death, is immediately life-threatening, results in persistent or signficant disability/incapacity, requires or prolongs patient hospitalisation, is a congenital anomaly/birth defect, or is deemed serious for any other reason. 'With or without other glucose-lowering medication. Hypoglycaemic AEs defined as those resulting in plasma glucose of at most $3.9 \mathrm{mmol} / \mathrm{L}$ and/or requiring assitance. AE = adverse event; eGFR = estimated glomerular filtration rate; MedDRA = Medical Dictionary for Regulatory Activities; URTI = upper respiratory tract infection.

The SGLT2 inhibitors canagliflozin, dapagliflozin and ertugliflozin are approved to lower blood sugar as an adjunct to diet and exercise.23-29 In the CANVAS study, canagliflozin was shown to improve CV outcomes in patients with T2D and CV risk factors, with a $14 \%$ reduction of the primary 3-point MACE outcome. ${ }^{16}$ However, unlike empagliflozin, canagliflozin did not reduce either $\mathrm{CV}$ or all-cause mortality. ${ }^{16}$ Both empagliflozin and canagliflozin reduced HF hospitalisation and improved renal outcomes. ${ }^{16}$ An overview of the primary, key secondary and safety outcomes in EMPA-REG OUTCOMES study and CANVAS study are shown in Table 4

\section{Glycaemic control}

During pre-registration phase III development, empagliflozin was assessed in several randomised controlled trials for the reduction of $\mathrm{HbA} 1 \mathrm{C}$ versus placebo, sitagliptin, glimepiride, linagliptin and metformin. ${ }^{59-70}$ Patients received empagliflozin as add-on to metformin, ${ }^{59}$ metformin + sulfonylurea, ${ }^{60}$ pioglitazone \pm metformin, ${ }^{61}$ basal insulin, ${ }^{62}$ multiple daily injections of insulin ${ }^{63}$ or were drug-naïve/pre-treated with any oral anti-diabetes therapy. ${ }^{64,65}$

Reductions in HbA1C levels from baseline to 12-24 weeks were greater for empagliflozin versus placebo, and empagliflozin also reduced BP and improved weight loss versus placebo. ${ }^{59-65}$ However, it should be noted that reductions in $\mathrm{HbA} 1 \mathrm{C}$ depend upon baseline levels; patients with baseline HDA1C $10.0 \%$ can expect about a $2 \%$ decrease, whereas from a starting point of $\mathrm{HbA} 1 \mathrm{C} 7.5 \%$, reductions were more modest at about $0.5 \% .^{59-65}$ In a study of empagliflozin versus glimepiride, both added to metformin, reductions in HbA1c levels were similar between groups, although glimepiride was associated with weight gain (mean $1.6 \mathrm{~kg}$ ), and empagliflozin was associated with weight loss (mean $-3.2 \mathrm{~kg}$ ). ${ }^{69}$

The results of ten phase III trials of empagliflozin in patients with T2D were analysed in a recent systematic review which reported that when used as an add-on treatment to metformin, empagliflozin improved long-term $\mathrm{HbA} 1 \mathrm{C}$ levels compared with glimepiride, and had a similar effect as linagliptin and sitagliptin. ${ }^{71}$ The analysis also showed that the combination of metformin and empagliflozin was well-tolerated with minimal hypoglycaemia.

\section{Clinical guidelines}

The American Diabetes Association (ADA) and Diabetes Canada guidelines recommend that either empagliflozin or liraglutide should be considered in patients with T2D and established CVD. ${ }^{72-4}$ The Canadian Diabetes Association (CDA) treatment guidelines (2016) recommend that for patients in whom glycaemic targets are not met, empagliflozin or liraglutide should be added to metformin as the optimal second-line choice to reduce the risk of $\mathrm{CV}$ death. ${ }^{74}$ Empagliflozin is recommended by the European Society of Cardiology (ESC) Heart Failure guidelines for the prevention of $\mathrm{HF}$ and reduction of $\mathrm{CV}$ mortality in patients with diabetes and established CVD. The ESC guidelines for CVD prevention in clinical practice state that, 'empagliflozin demonstrated substantial reductions in CV death (by 38\%) and all-cause mortality (by 32\%), as well as hospitalisation for HF (by $35 \%$ ), as compared with standard care, suggesting use of an SGLT2 inhibitor should come very early in the course of management of patients with diabetes mellitus and CV disease'. ${ }^{75,76}$ 
Table 4: Overview of sodium-glucose cotransporter 2 inhibitor outcome trials in patients with type 2 diabetes and cardiovascular disease

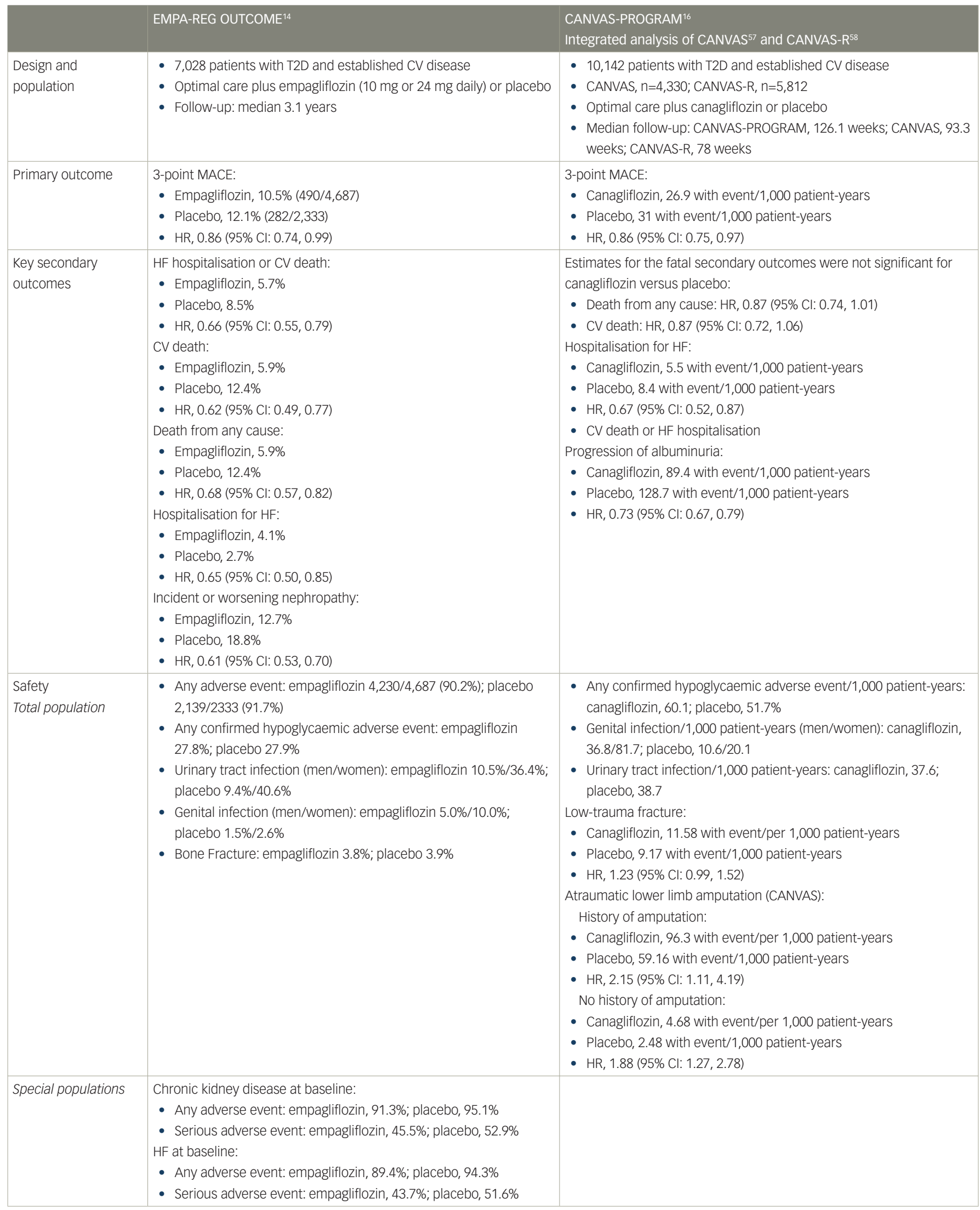

3-point MACE = Major Adverse Cardiac Events (defined as a composite outcome of death from CV causes, nonfatal myocardial infarction or nonfatal stroke); CANVAS = canagliflozin

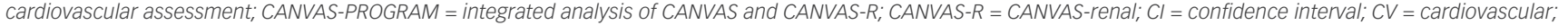
EMPA-REG OUTCOME = empagliflozin, cardiovascular outcomes and mortality in type 2 diabetes study; $H F=$ heart failure; $H R=$ hazard ratio; $T 2 D=$ type 2 diabetes. 


\section{Conclusions}

In patients with T2D, modulation of glucose-handling by the kidney with SGLT2 inhibitors lowers HbA1c levels, decreases body weight and visceral adiposity and improves cardio-renal haemodynamics. Currently, four SGLT2 inhibitors are approved in the US and Europe to improve glycaemic control. Empagliflozin is the only SGLT2 inhibitor that is indicated to reduce the risk of CV death in adults with T2D and CVD. In the overall population, and across a wide range of baseline subgroups such as $\mathrm{HbA} 1 \mathrm{c}$ level, renal function (down to eGFR $30 \mathrm{ml} / \mathrm{min} / 1.73 \mathrm{~m}^{2}$ ) and HF risk, empagliflozin reduced the risk of CV death, all-cause death and hospitalisation for HF. These findings suggest that empagliflozin should be considered in patients with T2D and CVD to reduce the risk of CV and all-cause death. $\square$
1. Sarwar N, Gao P, Seshasai SR, et al. Diabetes mellitus, fasting blood glucose concentration, and risk of vascular disease: a 2010;375:2215-22.

2. Di Angelantonio $E$, Kaptoge $S$, Wormser $D$, et al. Association of Cardiometab

3. Cubbon RM, Adams B, Rajwani A, et al. Diabetes mellitus is associated with adverse prognosis in chronic heart failure of ischaemic and non-ischaemic aetiology. Diab Vasc Dis Res. 2013;10:330-6.

4. Gæde P, Oellgaard J, Carstensen B, et al. Years of life gained by multifactorial intervention in patients with type 2 diabetes mellitus and microalbuminuria: 21 years follow-up on the Steno-2 randomised trial. Diabetologia. 2016;59:2298-307. Dormandy JA, Charbonnel B, Eckland DJ, et al. Secondary prevention of macrovascular events in patients with type 2 diabetes in the PROactive Study (PROspective pioglitAzone Clinical Trial In macrovascular Events): a randomised controlled trial. Lancet. 2005;366:1279-8

Duckworth W, Abraira C, Moritz T, et al. Glucose control and vascular complications in veterans with type 2 diabetes. N Eng J Med. 2009:360:129-39.

7. Marso SP, Daniels GH, Brown-Frandsen K, et al. Liraglutide and 2016:375:311-22.

8. Patel A, MacMahon S, Chalmers J, et al. Intensive blood glucose control and vascular outcomes in patients with type 2 diabetes.

9. Scirica BM, Bhatt DL, Braunwald E, et al. Saxagliptin and cardiovascular outcomes in patients with type 2 diabetes

mellitus. N Eng J Med. 2013;369:1317-26.

White WB, Cannon CP, Heller SR, et al. Alogliptin after acute coronary syndrome in p

11. Gerstein $\mathrm{HC}$, Miller ME, Byington RP, et al. Effects of intensive glucose lowering in type 2 diabetes. N Eng $J$ Med. 2008;358:2545-59.

12. Zoungas S, Chalmers J, Neal B, et al. Follow-up of bloodpressure lowering and glucose control in type 2 diabetes. N Eng J Med. 2014;371:1392-406.

13. Holman RR, Paul SK, Bethel MA, et al. 10-year follow-up of intensive glucose control in type 2 diabetes. N Eng J Med. 2008:359:1577-89.

14. Zinman B, Wanner C, Lachin JM, et al. Empagliflozin, Cardiovascular Outcomes, and Mortality in Type 2 Diabetes. N Eng J Med. 2015;373:2117-28.

15. Marso SP, Bain SC, Consoli A, et al. Semaglutide and Cardiovascular Outcomes in Patients with Type 2 Diabetes. $N$

16. Neal B, Perkovic V, Mahaffey KW, et al. Canagliflozin and Cardiovascular and Renal Events in Type 2 Diabetes. N Eng 」 777:644-57.

17. Kanai Y, Lee WS, You G, et al. The human kidney low affinity (n) renal reabsorptiven

18. Bakris GL, Fonseca VA, Sharma K, Wright EM. Renal sodiumglucose transport: role in diabetes mellitus and potential clinical implications. Kidney Int. 2009:75:1272-7.

19. Liu JJ, Lee T, DeFronzo RA. Why Do SGLT2 inhibitors inhibit only $30-50 \%$ of renal glucose reabsorption in humans? Diabetes. 2012;61:2199-204.

20. Rahmoune $\mathrm{H}$, Thompson PW, Ward JM, et al. Glucose transporters in human renal proximal tubular cells isolated from the urine of patients with non-insulin-dependent diabetes Diabetes. 2005;54:3427-34.

21. Heerspink HJ, Perkins BA, Fitchett DH, et al. Sodium Glucose Cotransporter 2 Inhibitors in the Treatment of Diabetes Mellitus Cardiovascular and Kidney Effects, Potential Mechanisms, and Clinical Applications. Circulation. 2016;134:752-72.

22. Kohler S, Zeller C, lliev H, Kaspers S. Safety and Tolerability of Empagliflozin in Patients with Type 2 Diabetes: Pooled Analysis

of Phase I-III Clinical Trials. Adv Ther. 2017;34:1707-26.

Bristo (dapagifiozin) tablets. Prescribing information Bristol-Myers Squibb Company Princeton, NJ 08543 and Available at: https://www. accessdata.fda.gov/drugsatfda_docs/ label/2014/202293s003lbl.pdf [accessed 31 May 2018].

24. Forxiga $5 \mathrm{mg}$ film-coated tablets. Summary of product characteristics. AstraZeneca AB SE-151 85 Södertälie Sweden. Available at: $h$ ttp:///www.ema.europa eu/docs/en GB/ document_library/Referrals_document/SGLT2_inhibitors_20/ European Commission final_decision/WC500206510.pdf [accessed 31 May 2018].

25. Invokana $100 \mathrm{mg}$ film-coated tablets Invokana $300 \mathrm{mg}$ filmcoated tablets. Summary of Product Characteristics. JanssenCilag International NV Turnhoutseweg, Belgium. Available at: http://Www.ema.europa.eu/docs/en_GB/document_library/
EPAR_-_Product_Information/human/002649/WC500156456 pdf [accessed 31 May 2018]

26. INVOKANA ${ }^{\oplus}$ (canagliflozin) tablets. Summary of Product Characteristics. Available at: http://www.ema.europa.eu/ docs/en_GB/document_library/EPAR_-_Product_Information/ human/002649/WC500156456.pdf [accessed $31 \mathrm{May} 2018$ ].
Jardiance $10 \mathrm{mg}$ film-coated tablets Jardiance $25 \mathrm{mg}$ film-

7. Jardiance $10 \mathrm{mg}$ film-coated tablets Jardiance $25 \mathrm{mg}$ film-
coated tablets. Summary of Product Characteristics. Boehringer cont//nternational at: http://WwW.ema.europa.eu/docs/en_GB/document_library/ pdf [accessed 31 May 2018]

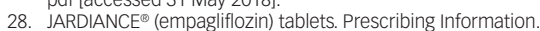

Boehringer Ingelheim International GmbH, Ingelheim, Germany. Avallable at: hitps.//Www.accessdata.fad.gov/drugsat/da_docs/

label/2016/20465//Ming

Merch \& Co., Inc, Whitehouse Station, NJ 08889, USA. Available Merch \& CO., Inc, Whitehouse Station, NJ 08889, USA.
at: https://www.accessdata.fda.gov/drugsatfda_docs/ label/2017/209803s000lbl.pdf [accessed 31 May 2018]

30. Grempler R, Thomas L, Eckhardt M, et al. Empagliflozin, a novel selective sodium glucose cotransporter-2 (SGLT-2) inhibitor:
characterisation and comparison with other SGLT-2 inhibitors. Diabetes Obes Metab. 2012:14:83-90

31. Jiang M, Steyger PS. An evaluation of US patent 2015065565 (A1) for a new class of SGLT2 inhibitors for treatment 1 of type diabetes mellitus. Expert Opin Ther Pat. 2015;25:1349-52

32. Miao Z, Nucci G, Amin N, et al. Pharmacokinetics, metabolism, and excretion of the antidiabetic agent ertugliflozin (PF04971729) in healthy male subjects. Drug Metab Dispos. 2013;41(2):445-56

33. Kalgutkar AS, Tugnait $\mathrm{M}$, Zhu T, et al. Preclinical species and human disposition of PF-04971729, a selective inhibitor of the sodium-dependent glucose cotransporter 2 and clinical candidate for the treatment of type 2 diabetes mellitus. Drug Metab Dispos. 2011;39:1609-19.

34. Fitchett D, Zinman B, Wanner C, et al. Heart failure outcomes with empagliflozin in patients with type 2 diabetes at high
cardiovascular risk: results of the EMPA-REG OUTCOME $\AA$ trial. Eur Heart I. 2016:37:1526-34.

35. Wanner C, Inzucchi SE, Lachin JM, et al. Empagliflozin and Progression of Kidney Disease in Type 2 Diabetes. N Eng $J$ Med :375:323-34

36. Fitchett $D$, Butler J, van de Borne $P$, et al. Effects of empagliflozin on risk for cardiovascular death and heart failure hospitalization across the spectrum of heart failure risk in the

EMPA-REG OUTCOME $\circledast$ trial. Eur Heart J. 2018;39:363-70. Bailey RA, Wang Y, Zhu V, Rupnow MF. Chronic kidney disease in US adults with type 2 diabetes: an updated national estimate of prevalence based on Kidney Disease: Improving
Global Outcomes (KDIGO) staging. BMC Res Notes. 2014:7:415.

38. Wu B, Bell K, Stanford A, et al. Understanding CKD among patients with T2DM: prevalence, temporal trends, and treatment patterns-NHANES 2007-2012. BMJ Open Diabetes Res Care. 2016;4:e000154

39. UK Prospective Diabetes Study (UKPDS) Group. Effect of intensive blood-glucose control with metformin on complications in overweight patients with type 2 diabetes (UKPDS 34). Lancet. 1998;352:854-65.

4. Coca SG, ISmail-Beigi F, Haq N, et al. Role of intensive glucose control in development of renal end points in type 2 diabetes mellitus: systematic review and meta-analysis
intensive glucose control in type 2 diabetes. Arch Intern Med. intensive glucose

41. Molitch ME, Adler Al, Flyvbjerg A, et al. Diabetic kidney disease: a clinical update from Kidney Disease: Improving Global a clinical update from Kidney Disease:
Outcomes. Kidney Int. 2015;87:20-30.

42. Perkovic V, Heerspink HL, Chalmers J, et al. Intensive glucose control improves kidney outcomes in patients with type 2 diabetes. Kidney Int. 2013;83:517-23.

43. Wanner C, Lachin JM, Inzucchi SE et al. Empagliflozin an Clinical Outcomes in Patients with Type 2 Diabetes, Established Cardiovascular Disease and Chronic Kidney Disease. Circulation. 2018;137:119-29.

44. Cherney DZI, Zinman B, Inzucchi SE, et al. Effects of empagifflozin on the urinary albumin-to-creatinine ratio in patients with type 2 diabetes and established cardiovascular disease: an exploratory analysis from the EMPA-REG OUTCOME randomised, placebo-controlled trial. Lancet Diabetes Endocrinol. 2017;5:610-21.

45. Inzucchi SE, Zinman B, Fitchett D, et al. How Does Empagliflozi Reduce Cardiovascular Mortality? Insights From a Mediation Analysis of the EMPA

46. Mudaliar S, Alloju S, Henry RR. Can a Shift in Fuel Energetics Explain the Beneficial Cardiorenal Outcomes in the EMPA-REG OUTCOME Study? A Unifying Hypothesis. Diabetes Care

7. Packer M. Do Sodium-Glucose Cotransporter-2 Inhibitors Counterbalancing the Effects of Leptin? A Novel Hypothesis Diabetes Obes Metab 2018:20:1361-1.

48. Packer M, Anker SD, Butler J, et al. Effects of Sodium-Glucose Cotransporter 2 Inhibitors for the Treatment of Patients With Heart Failure: Proposal of a Novel Mechanism of Action. IAMA Cardiol. 2017;2:1025-9.

49. Cavender MA, Steg PG, Smith SC, Jr., et al. Impact of Diabetes Mellitus on Hospitalization for Heart Failure, Cardiovascular Events, and Death: Outcomes at 4 Years From the Reduction of Atherothrombosis for Continued Health (REACH) Registry. Circulation. 2015;132:923-3

50. MacDonald MR, Petrie MC, Varyani F, et al. Impact of diabetes on outcomes in patients with low and preserved ejection fraction heart failure: an analysis of the Candesartan in Heart failure: Assessment of Reduction in Mortality and morbidity (CHARM) programme. Eur Heart J. 2008;29:1377-85,

1. Sarma S, Mentz RJ, Kwasny MJ, et al. Association between diabetes mellitus and post-discharge outcomes in patients
hospitalized with heart failure: findings from the EVEREST trial. Eur J Heart Fail. 2013;15:194-202.

52. Johansson I Edner M, Dahlström U, et al. Is the prognosis

in patients with diabetes and heart failure a matter of unsatisfactory management? An observational study from the Swedish Heart Failure Registry. Eur J Heart Fail. 2014:16:409-18.

53. Udell JA, Cavender MA, Bhatt DL, et al. Glucose-lowering

drugs or strategies and cardiovascular outcomes in patient with or at risk for type 2 diabetes: a meta-analysis of 2015:3.356-66.

54. Cherney DZ, Perkins BA, Soleymanlou N, et al. Renal hemodynamic effect of sodium-glucose cotransporter 2 inhibition in patients with type 1 diabetes mellitus. Circulation. 2014;129:587-97.

55. Tonneijck L, Muskiet MH, Smits MM, et al. Glomerular Hyperfiltration in Diabetes: Mechanisms, Clinical Significance, and Treatment. J Am Soc Neph. 2017;28:1023-39.

56. Škrtic M, Yang GK, Perkins BA, et al. Characterisation of glomerular haemodynamic responses to SGLT2 inhibition in patients with type 1 diabetes

57. Neal B, Perkovic V, de Zeeuw D, et al. Rationale, design, and baseline characteristics of the Canagliflozin Cardiovascular Assessment Study (CANVAS)--a randomized placebo-controlled trial. Am Heart J. 2013;166:217-23.e11.

58. Neal B, Perkovic V, Matthews DR, et al. Rationale, design and baseline characteristics of the CANagliflozin cardioVascular Assessment Study-Renal (CANVAS-R): A randomized, placebo-

controlled trial. Diabetes Obes Metab. 2017,19.387-93.

9. Häring HU, Merker L, Seewaldt-Becker E, et al. Empagliflozin as add-on to metformin in patients with type 2 diabetes: a
24 -week, randomized, double-blind, placebo-controlled trial. Diabetes Care. 2014;37:1650-9.

60. Häring HU, Merker L, Seewaldt-Becker E, et al. Empagliflozin as add-on to metformin plus sulfonylurea in patients with type 2 diabetes: a 24-week, randomized, double-blind, placebo-

61. Kovacs CS, Seshiah V, Swallow R, et al. Empagliflozin improves glycaemic and weight control as add-on therapy to pioglitazone
or pioglitazone plus metformin in patients with type 2 diabetes: 24-week randomized placebo-controlled trial. Diabetes Obes Metab. 2014;16:147-58.

62. Rosenstock J, Jelaska A, Zeller C, et al. Impact of empagliflozin added on to basal insulin in type 2 diabetes inadequately controlled on basal insulin: a 78-week randomized, doub 2015;17:936-48.

63. Rosenstock J, Jelaska A, Frappin G, et al. Improved glucose control with weight loss, lower insulin doses, and no increased hypoglycemia with empagliflozin added to titrated multiple daily injections of insulin in obese inadequately controlled type 2 diabetes. Diabetes Care. 2014;37:1815-23.

64. Barnett AH, Mithal A, Manassie J, et al. Efficacy and safety of empagliflozin added to existing antidiabetes treatment in randomised, double-blind, placebo-controlled trial. Lancet Diabetes Endocrinol. 2014:2:369-84.

65. Tikkanen I, Narko K, Zeller C, et al. Empagliflozin reduces blood pressure in patients with type 2 diabetes and hypertension. Diabetes Care. 2015;38:420-8

66. DeFronzo RA, Lewin A, Patel S, et al. Combination of empagliflozin and linagliptin as second-line therapy in subjects with type 2 diabetes inadequate

Diabetes Care. 2015;38:384-93. empagliflozin and linagliptin in subjects with type 2 diabetes. Diabetes Care. 2015;38:394-402

68. Hadjadj S, Rosenstock J, Meinicke T, et al. Initial Combination of Empagilflozin and Metformin in Patients With Type 2 Diabetes. Diabetes Care. 2016;39:1718-28.

69. Ridderstråle $\mathrm{M}$, Andersen $\mathrm{KR}$, Zeller $\mathrm{C}$, et al. Comparison of empagliflozin and glimepiride as add-on to metformin in patients with type 2 diabetes: a 104-week randomised, active-controlled, double-blind, phase 3 trial. Lancet Diabetes

70. Roden M, Weng J, Eilbracht J, et al. Empagliflozin monotherapy with sitagliptin as an active comparator in patients with type 2 diabetes: a randomised, double-blind, placebo-controlled,
phase 3 trial. Lancet Diabetes Endocrinol. 2013;1:208-19.

71. Anderson JE, Wright EE, Jr., Shaefer CF, Jr. Empagliflozin: Role in Treatment Options for Patients with Type 2 Diabetes Mellitus. Diabetes Ther 2017:8:33-53.

72. American Diabetes Association. Approaches to glycemic treatment. Diabetes Care. 2016;39 Suppl 1:S52-9. hyperglycemia in type 2 diabetes, 2015: a patient-centered approach. update to a position statement of the American Diabetes Association and the European Association for the Study of Diabetes. Diabetes Care. 2015:38:140-9.

7. Canadian Diabetes Association Clinical Practice Guidelines Expert Committee. Pharmacologic Management of Type 2 Diabetes: 2016 Interim Update. Can J Diabetes. 2016;40:193-5. . Piepoli MF, Hoes AW, Agewall S, et al. 2016 European Guide on cardiovascular disease prevention in clinical practice: The Sixth Joint Task Force of the European Society of Cardiology and Other Societies on Cardiovascular Disease
Prevention in Clinical Practice (constituted by representatives of 10 societies and by invited experts) Developed with the special contribution of the European Association for Cardiovascular Prevention \& R
Eur Heart J. 2016:37:2315-81.

76. Ponikowski P, Voors AA, Anker SD, et al. 2016 ESC Guidelines for the diagnosis and treatment of acute and chronic hear acute and chronic heart failure of the European society of 